\title{
Green Signalling Effects in the Market for Energy-Efficient Residential Buildings
}

\author{
BY FrANZ FUERST ${ }^{*}{ }^{1}$, ELIAS OIKARINEN*** \& OSKARI HARJUNEN***
}

\begin{abstract}
Empirical evidence from recent studies suggests that the price premium on energy-efficient buildings is potentially higher than the pure capitalisation of energy savings but the empirical evidence on the size of the non-savings components is scant. This study aims to fill this research gap by investigating whether the mandatory energy efficiency ratings for residential properties imply benefits that go beyond energy savings. Using a sample of several thousand apartment transactions from Helsinki, Finland, we first test if higher ratings were significantly associated with higher prices. In addition to a large number of property and neighbourhood characteristics, this dataset contains information on building-level energy usage which allows us to distinguish between the cost savings effect of energy consumption and the value of more intangible factors associated with the energy label. The hedonic model yields a statistically significant 3.3\% price premium for apartments in the top three energy-efficiency categories and 1.5\% when a set of detailed neighbourhood characteristics are included. When maintenance costs containing energy usage costs are added, a robust and significant price premium of $1.3 \%$ persists whereas no differentiation is found for the medium and lower rating categories. These findings may be indicative of energy-efficient buildings having signalling value - and therefore an additional incentive to invest in such buildings - for 'green' consumers. However, a favourable energy rating did not appear to speed up the sales process in the analysed market.
\end{abstract}

Keywords: housing; signalling value; energy efficiency; energy performance rating; hedonic pricing; time on market

\footnotetext{
* University of Cambridge, ** University of Turku, *** City of Helsinki Urban Facts

${ }^{1}$ Corresponding author: ff274@cam.ac.uk
} 


\section{Introduction}

An emerging strand of literature into energy efficiency suggest that indirect and intangible benefits of energy efficiency improvements may play a previously underestimated role. For example, Gliedt and Hoicka (2015) find that corporate social responsibility can act as an additional driver for energy performance improvements in the commercial real estate market. This finding is pertinent as expected cost savings alone are frequently not sufficient to trigger an investment decision (Popescu et al., 2012). The presence of notable and well-documented financial, institutional and behavioral barriers to invest in energy efficiency implies that such non-savings related incentives may be required to close the energy efficiency gap (Jackson, 2010; Gliedt and Hoicka, 2015). Therefore, Identifying and quantifying multiple benefits of energy efficiency are of increasing relevance in energy efficiency research (Popescu et al., 2012).

One of the key sectors in the aims to curb energy consumption is the housing sector: Buildings are the largest source of greenhouse gas emissions in the world and represent the biggest sector of primary energy consumption, and housing units account for a major part of these emissions and consumption. Hence, from a welfare economic point of view the issue of providing adequate incentives for building and investing in energy efficient housing is of particular importance. The aim of this study is to investigate whether mechanisms that are similar to the corporate social responsibility factor reported by Gliedt and Hoicka (2015) are present in the housing market. In particular, we test for the presence and value of a green signalling effect in addition to any cost savings. asignalling.

Energy efficiency measures and the energy saving potential related to buildings as well as the valuation effects of these measures and savings have become a prominent research subject around the world. This strand of scientific literature includes studies on the effect of heating systems (Joelsson and Gustavsson, 2009) and the building envelope (Balaras et al., 2005; Lechtenböhmer and Schüring, 2010; Thorsnes and Bishop, 2013; Arumägi and Kalamees, 2014) on the energy performance and value of housing, the influence of climatic conditions on energy saving measures and the energy demand of buildings (Considine, 2000; Aktacir et al., 2010; Rahman et al., 2010; Moustris et al., 2014) as well as the decision-making process that leads to energy performance improvements in the real estate sector (Gliedt and Hoicka, 2015). The role of home efficiency rating systems in providing important information to consumers is highlighted by Wong-Parodi et al (2016). Transparency about the energy efficiency status of a property enables consumers to make an informed choice when acquiring a property. Nevertheless, the pricing of energy-efficient residential buildings has been a largely understudied topic relative to its obvious relevance for both the general economy and sustainable development. The reasons for this lack of empirical evidence are not clear, but the greater fragmentation of investors and lower fraction of 
professional or institutional investment compared to the commercial real estate market may be a contributing factor. Also, residential property markets are highly regulated and prone to market inefficiencies. Generally, the more inefficiently a market operates, the more difficult it will be to isolate a hedonic price signal of an individual characteristic. Moreover, green financial instruments are still not used widely in the residential sector, which makes capitalisation into the lump-sum house price the only channel for economic rewards of sustainability in many cases. As this poses a significant risk for any upfront investment in energy efficiency, 'green value' might not be readily observable in many housing markets. Kauffman and Garafola (2016) point out that quantifying the savings from higher energy efficiency levels has been largely neglected by homeowners as all potential savings accrue only to them. This means that once the investment is made, it becomes akin to a sunk cost and no accurate measurements of the actual subsequent savings and beneifts is usually undertaken, The authors conclude that a change is unlikely to occur unless a business model is developed by which an external party reaps part or all of the benefits of an energy efficiency upgrade and the affected parties will want to know their individual shares of costs and benefits.

Despite these complications, the early study of Dian and Miranowski (1989) was one of the first to suggest a direct link between the level of energy efficiency and the value of a property. More recently, Wameling (2010) reported higher selling prices for dwellings with lower primary energy demand in the German housing market, and Kahn and Kok (2014) arrived at similar conclusions in their study of the Californian housing market. The results by Harjunen and Liski (2014), in turn, indicate that the heating energy costs capitalise in prices in the Helsinki single-family housing market in Finland. Similar observations have been reported for Asian markets as well: Zheng and Kahn (2008) and Zheng et al. (2012) found significant price premia for green housing in China, and Deng et al. (2012) observed substantial economic returns to green housing in Singapore.

The extant literature on potential additional drivers to invest in energy efficient housing is particularly scarce. In related studies, Banfi et al. (2005), Burfurd et al. (2012) and Fuerst et al. (2015) published findings indicating that rental housing tenants are prepared to pay higher rent for buildings that have adopted energy-saving measures. Burfurd et al. (2012) used laboratory experiments to show that information on the energy efficiency of a dwelling - either mandatory or voluntary - improves the market efficiency and increases investment in energy efficiency in the housing rental market, while the lack of information can give rise to an undesirable 'lemons market' outcome. Based on data for Stockholm in Sweden, Mandell and Wilhelmsson (2011) concluded that there is a positive willingness to pay for environmental attributes and this willingness is greater for those households who state that they are environmentally aware. Popescu et al. (2012), in turn, 
report evidence suggesting that the added value due to energy performance should be taken into consideration when the financial analysis within the energy audit is performed.

Given the importance of the topic and scarcity of research on it, there is a large demand for more research on other potential incentives for investment in energy efficient housing. This article aims to provide new knowledge on the issue - knowledge that also is of practical importance having policy implications. In particular, we aim to bring more information on the influence of energy ratings on the value and liquidity of housing, including new knowledge on the willingness to pay for being green and on signaling household's green values to the peers. Such willingness to pay and signal to the peers - that corresponds closely to the corporate social responsibility effect reported by Gliedt and Hoicka (2015) - could act as an additional driver for investments on energy efficiency not only in the housing market, but in many other sectors too. In addition to investigating a different real estate sector, our analysis differs from that by Gliedt and Hoicka (2015) with respect to the research methodology. While their results are based on survey data, our empirical analysis uses detailed data on the actual housing transactions.

We use a dataset for the Helsinki metropolitan area in Finland for the period 2009-2012 that includes the transaction price, energy rating, and a great number of other variables describing the quality and location for each transacted unit. The cold climate of the study area makes the case study interesting also because the cost savings from insulation and thus from heating energy may be substantial. A greater number of heating-degree days has been consistently linked to higher energy demand in the residential sector (e.g. Considine, 2000; Moustris et al., 2014) which in turn means higher potential savings potential from more energy-efficient dwellings. While these climatedependent factors affect primarily the passive energy efficiency of a building, in particular heat loss-reducing measures, there is also an array of active systems involved in the energy performance rating that are not likely to be subject to thermal variations to the same extent such as energy monitoring and automation systems or potentially also on-site renewable energy generation.

In addition to giving information regarding a market with higher requirements regarding insulation, the dataset is valuable because it contains information on the actual maintenance costs, including energy consumption, and on the time on market of each unit in our sample. Hence, the data present us with an opportunity to examine whether the energy rating has its own independent impact over the maintenance cost information on housing values and liquidity. While e.g. Brounen and Kok (2012) showed that higher energy label induces a price premium and low-grade labels a price discount in the Netherlands, no study (to the best of our knowledge) has investigated whether the rating affects prices after the value of energy cost savings is taken into account in the estimated equation. That is, to our best knowledge there is no previous research giving information 
on the independent value of the energy efficiency rating and therefore on the potential incentives to invest in energy efficient housing created by the kind of rating system that is mandatory within the European Union.

Furthermore, while time on market was included in previous studies of energy efficiency capitalisation in house prices - for example by Kholodilin and Michelsen (2014), where this indicator is used as a control variable to adjust asking prices that are set too high by the landlord there appears to be no previous evidence on the direct link between time to sale and energy efficiency. Faster expected selling time could act as an additional incentive to invest in green housing.

Helsinki also is an interesting case market because of the detailed information on neighbourhood characteristics. In particular, the data enable us to account for these characteristics more carefully than in the previous related studies and thereby to extract the influence of energy grades more accurately. In addition, our analysis is based on an actual consumption-based rating unlike in extant studies, since the energy ratings were based on the actual observed energy consumption in Finland during our study period. As typically within the EU, the rating system includes seven categories, 'A' being the most energy efficient class with energy consumption of only $0-100 \mathrm{kwh} / \mathrm{m}^{2}$ per year, while ' $G$ ' is the most energy inefficient class (more than $280 \mathrm{kwh} / \mathrm{m}^{2}$ per year). A potential complication with the consumption-based system is that the observed energy consumption is dependent on the size and habits of households inhabting the building, not only on the building characteristics. In our study, this concern is mitigated by the fact that heating costs are averaged over all households in an apartment building and within-unit electricity consumption, for example for household appliances and electronic devices, is excluded from the energy performance rating. Based on our conceptual framework, we derive three hypotheses that we test empirically: 1) due to a 'signalling effect' that arises from signalling one's green values to the peers, the higher-tier ratings induce a premium in house prices, whereas the below average classes do not sell at a discount compared with the average energy efficiency dwellings, 2) the high-tier energy ratings affect the housing values even when controlling for the observed maintenance costs that include the energy costs, and 3) the estimated premium for energy efficient housing units decreases as confounding factors, detailed neighbourhood characteristics and maintenance cost in particular, are included in the price equation. Furthermore, we argue that it is impossible to derive a clear a priori expectation on the link between energy efficiency levels and liquidity (as measured by time on market) from theory as the hypothesised relationships work in opposite directions, potentially cancelling each other out.

Empirically, we find evidence in support of each of the three hypotheses. First, a statistically significant price premium only exists for the highest $(A B C)$ energy ratings and no impact is found 
for below average ratings. This implies that only a fraction of households are energy-aware and willing to pay a premium for more energy efficient housing. Secondly, the premium exists even when maintenance costs are included in the model as a control variable. If the energy ratings were only priced according to implied cost savings, we would expect the ratings to become insignificant in the hedonic estimation once maintenance costs are taken into account. A significant premium suggests that buyers consider additional factors in their implicit valuation of energy-efficient homes. This conjecture is in line with the findings of Gliedt and Hoicka (2015) and also supported by Popescu et al. (2012) who argue that factors other than the potential energy cost savings are at play when the economic value of energy efficiency improvements is measured. Third, while the valuation impact for high-rated units is significant in all model specifications, adding more careful neighborhood controls and maintenance costs substantially decreases the estimated premium. In contrast with the price effects, we do not detect any influence of energy ratings on the liquidity of housing.

The next section describes a conceptual framework to consider the pricing effects of housing energy efficiency ratings. A brief presentation of the Helsinki market is provided and the dataset used in the empirical analysis is delineated in section three. That section also includes a detailed description of the energy rating system in Finland. After that, we present the estimation approach and report the empirical results. Summary and conclusion, including a discussion of policy implications, are provided in the final section.

\section{A conceptual model of energy efficiency and house prices}

Every house purchase decision also entails an implicit or explicit decision about the desired level of energy efficiency. Leaving aside the rich literature on the limitations to rational decision-making for the moment, it is straightforward to assume that the utility a household derives from owning a dwelling can be written in Cobb-Douglas form:

$$
E\left(U_{n}\right)=\alpha \sum_{n=1}^{N}\left(e_{n}^{\beta}+x_{n}^{\gamma}\right)
$$

where $E\left(U_{n}\right)$ is the total utility of a dwelling $n$ which comprises energy efficiency $(e)$ and all other characteristics of the dwelling $(x)$. Each homebuyer then faces the decision of choosing the levels of energy efficiency and other characteristics with weights $\beta$ and $\gamma$ respectively that maximize their utility according to their individual preferences. The choice of a level of energy efficiency is thus part of a larger bundle of characteristics of a property such as size, location, state of repair etc. and potentially correlated with these factors. For example, properties with state-of-the-art energy efficiency levels may be found in more affluent locations and also be larger and better maintained than properties with lower energy ratings. Matisoff et al (2014) posit in the context of firm 
production functions that higher $e$ is not only associated with cost savings via lower energy consumption but also creates a competitive advantage via a 'green' signal to consumers from environmentally friendly investment. In a similar vein, Gliedt and Hoicka (2015), present empirical evidence of Cooreman's (2011) contention that investments in energy efficiency are not only motivated by financial but also by strategic considerations in the commercial real estate sector, for example in an effort to improve the brand image of a company. For the present study of the housing market, we seek to infer whether an analogous motivation exists for homebuyers, i.e. whether price differentials are motivated purely by utility bill savings or whether green consumers may also seek to increase their status by buying an energy-efficient home.

The utility of energy efficiency can be assumed to rise with each increment in the energy rating albeit at an increasing marginal rate. The concept of increasing marginal utility in relation to social and economic status gains has been developed by Friedman (1953), Lommerud (1989) and corroborated by more recent work, for example by Ray and Robson (2010). While the cost savings associated with higher energy efficiency can be viewed as quasi-linear, the signalling value of energy ratings increases in non-linear fashion. In other words, all dwellings above the lowest grade show energy cost savings, but only the above-average rated dwellings will have additional signaling value attached to them that allows households to visually demonstrate their environmentally conscious values and behaviour to their peers. Thus, the utility derived from the energy efficiency level of a dwelling is a combination of the linear utility of the cost savings (cs) from energy efficiency and the convex utility of the signalling value (sv).

$$
e_{n}=c s_{n}+s v_{n}^{\partial}
$$

The willingness to pay for a given step increase in energy efficiency equals then the total marginal utility increase from linear cost savings and the non-linear signaling value.

It is important to note that demand for the higher tier of energy efficiency investments may not be distributed equally across all homebuyers. Some buyers may derive higher utility from living in greener dwellings than others because of their intrinsic environmental values and preferences and/or the collective environmental attitudes of their peer group to which they may signal housing consumption that is in line with these attitudes by buying 'greener' apartments. This may give rise to a 'green signalling effect' where only a fraction of households are willing to pay a premium for superior energy performance while most households do not place any value on energy ratings.

Based on the above conceptual framework, three hypotheses can be developed and tested empirically: 1) the signalling effect, arising from signaling values to the peers, increases demand for the high-rated dwellings inducing a price premium for them, whereas the below average classes 
do not sell at a discount compared with the average energy efficiency dwellings, 2) the higher-tier energy ratings affect the housing values and liquidity even when controlling for the observed maintenance cost that include the energy costs, and 3) the estimated premium for energy efficient housing units decreases as confounding factors, notably location, maintenance cost and dwelling condition are included in the price equation.

There are some intervening factors that may lead to non utility maximising outcomes, particularly with regard to the potential cost saving part of the utility function. Gillingham et al (2006) identify a number of market failures that lead to suboptimal investment levels in energy efficiency. More recently, Szumilo and Fuerst (2014) report a 'green operating expense puzzle', i.e. the total operating expenses of eco-certified commercial properties are higher, not lower, than those of comparable non-certified properties. The complexity of the interaction between the intrinsic energy efficiency of a property and behavioural factors governing actual energy demand may act to further confound the simple relationship between energy efficiency levels and observed pricing mechanisms. Finally, an absence of a price premium on energy savings may also indicate high discount rates of these future savings due to uncertainty and other factors such as a generally low rate of 'energy literacy' among homebuyers reported by Brounen et al. (2012). Studies of individual differences in discount rates also show that cognitive ability plays an important role. For example, Warner and Pleeter (2001) find that individuals with higher mental test scores have lower implicit discount rates, possibly because of a larger capacity to understand intertemporal choices and longterm investment decisions. These differences at the individual level may then lead to observable differences in the pricing of energy efficiency among different groups of buyers despite the seemingly identical and linear cost savings associated with energy efficiency levels.

\section{Helsinki Dataset and the Finnish energy efficiency rating system}

This study is based on transaction level housing sales data for the Helsinki metropolitan area (HMA) from 2009 to 2012. The HMA contains Helsinki, the capital of Finland, and the two municipalities surrounding it (Espoo and Vantaa), and is by far the largest metro area in Finland with its 1.1 million inhabitants. These HMA data are used to investigate the influence of energy ratings on housing sales prices and time on market.

Our data consist of second-hand transactions of privately financed apartments. That is, the data exclude newly built dwellings. There are good reasons to focus on the privately financed (i.e. nonsubsidised) sector only: In Finland, privately financed housing can be bought and sold at market prices without any restrictions, whereas selling prices and rental prices are controlled in the publicly regulated (i.e. subsidised) sector. Furthermore, the data consist only of apartments, since 
data on apartments are more reliable than data on the other housing types in the HMA. Apartments are the dominant housing type in the area (75\% of dwellings are apartments) and a substantially more homogenous group in their characteristics than the other housing types. Moreover, a notably greater number of transactions take place in the apartment market than in the market for other housing types. Therefore, the use of apartment data diminishes the heterogeneity complication that may be associated with housing price analysis even when hedonic modelling techniques are applied. A similar rationale applies to energy consumption which would be problematic to compare across different house types and regions due to the interaction with multiple confounding factors (Heinonen and Junnila, 2014). In 2012, the total number of permanently occupied apartment units in the HMA was 417 900, while the whole housing stock included 554000 occupied dwellings.

From a construction company's / developer's point of view, it would be particularly interesting to know the value of energy efficiency regarding new housing construction. The study excludes new builds, though. Nevertheless, even the data on secondary market transactions is expected to reveal important information concerning the value of newly built housing, since new dwellings and older stock can generally be considered as close substitutes for each other - the same hedonic pricing principles and values must largely apply to newly built housing as to the existing housing stock.

The housing transaction data are provided by the private real estate agency Kiinteistömaailma. The data include all the apartment transactions made using this agency's services, i.e., approximately $25 \%$ of all the transactions in the area during the sample period. The data contain detailed information on the characteristics of each transacted unit, such as age, size, address etc. Our sample consists of 6203 observations with an energy efficiency rating, of which 9 were excluded from the analysis as obvious price anomalies with more than three standard deviations from the mean price per square metre. The selection of key characteristics that we include in the analysis is presented in Table 1.

Compared to data provided by the Finnish Real Estate Federation, the distribution of energy ratings in our sample is largely in line with the energy rating distribution in the whole stock of apartments in Helsinki. We report the characteristics separately for four different energy efficiency groups, since we use this grouping in the econometric estimations. As the number of $A(23)$ and $B$ (102) rated observations is very small, we combine the three high-tier bands so that the top-tier energy efficiency group ( $A B C)$ comprises 631 observations. In line with the overall Helsinki apartment stock, the share of the $A B C$ group is some $10 \%$ of our sample. We consider this the target group of dwellings for green consumers in our signalling effect hypothesis. This also reflects the fact that it is hard to achieve higher than the average energy efficiency rating in the Finnish market. We also combine the two lowest ratings, i.e. F and G, because separately especially $G$ 
would have too small a number of observations (101) for a reliable analysis. As shown in Table 1, most of the units are either $D$ or $E$ rated. The most common rating is $D$ with $44 \%$ of the overall sample being rated in this medium category.

\section{[Table 1 around here]}

The average transaction prices are in line with market observations as reported by Statistics Finland. The characteristics considered here include the standard hedonic characteristics such as age, size and location as well as a number of more specialised features. For example, a sauna is considered to add value to a housing unit in the Finnish context due to its importance in Finnish cultural tradition. A notable share of apartments includes a sauna. Note also that the data allow us to include detailed variables on the floor and building height, and importantly on both the road distance to $\mathrm{CBD}$ and the travel time to the CBD using public transportation obtained from MetropAccess (2014) Travel Time Matrix.

Our neighborhood measures are obtained from Statistics Finland's grid database 2010. This database is based on $250 \times 250$ meter grids and includes a number of relevant variables for housing values, in addition to grid coordinates. These variables contain information about the socioeconomic structure and the housing stock of the neighborhoods. In Helsinki, as in many other cities around the world, neighborhoods can be quite small in area, and there can be 'good' and 'bad' neighborhoods in close proximity. Thus, it is important to be able to include detailed neighborhood information in the hedonic analysis as pointed out in several seminal papers (e.g. Rosen, 1974; Bartik, 1987; Malpezzi, 2003). The lower part of Table 1 contains key descriptive statistics for the neighborhood measures used in the analysis.

With respect to most characteristics, the differences across the three energy efficiency classes are only small. The average per sqm selling price of the high-rated (ABC) units is somewhat greater than that of the $D$ and $E$ rated units. However, the average transaction price is the highest for the low energy efficiency class (FG). The high-rated apartments are a bit larger than the other ones, on average. Generally, the $A B C$ rated units are located slightly further away from the $C B D$, which is in line with the fact that they typically are newer. The most notable differences across the groups concern the dwelling condition and sauna variables: the mean values indicate that the high-rated units are in substantially better shape and are much more likely to include a sauna than the lowerrated ones.

Figure 1 shows the geographic distribution of observations for each of our four energy classes. In this figure, grey coloured areas are water. While the big picture regarding the locational distribution is similar for each class, there are some differences across the classes. Most notably, the number 
of FG observations is very small in the western part of HMA. In any matter, we control for the locational factors in great detail in the econometric analysis.

[Figure 1 around here]

\section{Energy efficiency rating and maintenance costs}

Since 2009, all flats that are on sale in Finland are required to obtain an energy efficiency certificate. However, during our sample period the certificate was voluntary for apartments in small housing companies, i.e., in companies with no more than six dwellings, that were built before 2008. The certificate reports the actual heating energy, cooling energy and (other) electricity usage of the building. The energy efficiency value is based on the actual observed energy consumption, and the energy usage values are stated as kWh per gross floor area $\left(\mathrm{m}^{2}\right)$ per year. This differs from the typical European case, where the energy efficiency rating is appraisal-based. The energy rating is valid for 10 years. Given the typical level of maintenance in the housing companies, the energy efficiency of a given building is unlikely to change within the 10 year period. During the sample period, the ratings were based on the following energy consumption bands:
A: $0-100 \mathrm{kwh} / \mathrm{m}^{2} /$ year
B: $101-120$
C: $121-140$
D: $141-180$
E: $181-230$
F: $231-280$
G: $281-$

Due to the cold winter in Helsinki with subzero long-term average lowest daily temperatures from November until March, buildings generally require good heat insulation regarding walls, floor, ceiling, loft, and windows to receive a high energy efficiency rating. A typical building that meets the requirements of building regulations set in 2008 is generally D rated. Ottelin et al. (2015) show that the emissions from housing energy are generally much lower in new buildings compared with the old stock in Finland, as expected.

Because the average outside temperature - and thereby the heating energy usage - can vary across years, the heating energy consumption is 'normalised'. The normalisation takes into account the difference between the average temperature of the year during which the energy consumption is observed and the long-term average annual temperature. 
The rating is the same for all the apartments within the same building, as the rating is given at the housing company level. Practically all apartments in Finland are part of a housing company. A potential complication with the rating system is that the observed energy consumption is dependent on the habits of people living in the building, not only on the building characteristics. Another complication is caused by the varying number of people per sqm living in different buildings, as the energy consumption is normalised only with respect to the floor area. Fortunately, the energy consumption that influences the energy rating is not largely dependent on the number of people staying in the building. This is because 1) the heating and cooling energy are typically only slightly affected by the number of dwellers and 2) electricity consumption used in the rating computations does not incorporate the electricity usage inside apartments - it only includes general building level electricity usage (heating, outside lighting, stairway lighting, and various building level machinery such as lifts, pumps etc.). The within-unit electricity consumption, i.e. lighting and various appliances such as TV and washing machines, is billed to each household separately: As this consumption is largely dependent on a household's size and habits, it does not enter the energy efficiency calculations apart from inside-unit water heating. The fact that withinunit energy consumption on the overall heating energy usage is generally only small - in 2011 the share was $17 \%$ in Finland according to Statistics Finland - diminishes the potential influence of this complication on the results. According to the Finnish Ministry of the Environment, there are no further significant complications pertaining to the energy efficiency ratings of apartments (although terraced and detached houses face such complications but this is outside the scope of this paper which focusses on apartments).

In Finland, each dwelling in a housing company is charged an identical monthly per square metre maintenance fee. While information on the maintenance costs are not available for most countries, in the Finnish context the company form of housing ownership allows for the recording of maintenance costs for practically all the apartment transactions. In the housing company form of housing ownership - which quite closely corresponds to the housing cooperative structure in some other countries - ownership of a certain set of shares of the company confers the right to use a certain part of the building owned by the company, and a transaction of shares refers to a sale of shares entitling right to use a given dwelling owned by the company. The owners pay a monthly fee towards maintenance costs. The maintenance cost fee is public information. One advantage of the housing company structure is risk pooling among the individual households owning units through shares. Another attractive feature is the economies of scale (with respect to maintenance) provided by a company owning a number of dwellings.

The maintenance costs charged by housing companies include the aforementioned company level energy consumption costs as well as several other expenditures including administration, cleaning 
services, refuse disposal, insurances, and real estate tax. Similar to the energy rating calculations, the company level maintenance costs do not incorporate the within-unit electricity consumption, for which households are billed individually. According to Statistics Finland, the average share of heating energy expenditure of the overall maintenance costs of Helsinki area apartment stock was $20 \%$ in 2010-2011. Corresponding values for electricity and gas was $3 \%$, and $7 \%$ for water (including sewage). The relatively small share of gas and electricity can be explained by the fact that a great majority of the buildings are heated through central/district heating. According to Statistics Finland, 86\% of heating energy of the whole Finnish stock of apartments was supplied via district heating in 2011. While our maintenance cost variable incorporates costs stemming from the building level energy usage, separate data on the actual energy consumption or costs are not available. It is also worth noting that the results of our analysis are mainly reflective of the situation in the bulk of the housing stock that uses district heating. The results could potentially be different for stock with other configurations and billing arrangements.

However, as the main research question is whether the ratings contain independent pricing information in excess of the maintenance costs including prevailing energy usage costs, and information affecting the liquidity of apartments, the caveats mentioned above should not cause notable complications. In particular, a finding that the energy ratings have pricing information even in a model including maintenance costs would indicate that the ratings contain independent value and information.

The summary statistics in Table 1 provide an indication of the link between the energy performance rating and average maintenance cost. The top section of Table 1 shows that average monthly maintenance costs per square metre are $€ 3.08$ for the $A B C$ class, $€ 3.33$ and $€ 3.64$ for $D$ and $E$ rated units respectively, and $€ 3.74$ for the lowest energy efficiency class (FG). Since this difference in maintenance costs may be due to not strictly energy performance related factors, for example deteriorating building substance, higher replacement and redecoration requirements etc., we also provide a regression for the maintenance costs in Table 2. This regression that controls for other factors potentially affecting the maintenance costs, confirms that the costs are lower in the more energy efficient buildings. In other words, higher energy performance is associated with lower maintenance costs even when comparing buildings with a similar condition, that are of similar age, that have similar location, etc. The omitted energy class in the regression is $D$.

[Table 2 around here] 


\section{Empirical strategy and results}

In line with other studies in this topic area, we estimate hedonic housing price functions (Rosen, 1974), where the dependent variable is the natural log of the transaction price while the detailed housing characteristics are used as explanatory variables that determine the value of a dwelling. This allows us to estimate a separate value for each characteristic, i.e., a separate price function for housing. As our most extensive model, we estimate the following regression specification:

$$
\ln p_{i l t}=\beta E R_{i}+\lambda \text { Maint }_{i}+\gamma X_{i l}+n_{i l}+q_{i t}+\epsilon_{i l t}
$$

where

$$
\begin{aligned}
& \ln p_{i l t}=\text { natural log of transaction price (unit i, neighbourhood l, time t) } \\
& \left.\left.E R_{i}=\text { energy class } \text { high-rated ( } \mathrm{ABC}\right), \text { E-rated (E), low-rated (FG); omitted group = D }\right\} \\
& \text { Maint }_{i}=\text { maintenance costs per square meter } \\
& X_{i l}=\text { vector of house and neighbourhood characteristics } \\
& n_{i l}=\text { postal code fixed effects } \\
& q_{i t}=\text { year quarter fixed effects } \\
& \varepsilon_{i l t}=\text { error term. }
\end{aligned}
$$

$\beta$ is a four-dimensional vector of coefficients on the energy classes, $\gamma$ is the coefficient on maintenance costs, and $\lambda$ is a vector of coefficients on the house and neighbourhood characteristics. In all model specifications, $\beta, \gamma$ and $\lambda$ are estimated using the Ordinary Least Squares (OLS) technique controlling for the clustering of model residuals. The usual assumption that $\varepsilon_{i l t}$ is iid (independently and identically distributed), is probably violated in this case with multiple observations of flat sales over time in the same locations. In the presence of clustered errors, OLS estimates are unbiased but the standard errors can be wrong, thus leading to incorrect inference. A natural generalisation is to assume clustered standard errors such that observations within a postal code area are correlated in some unobserved way but that there are no correlated errors across postal code areas (Rogers, 1993).

By including the maintenance costs and energy efficiency ratings in the group of right hand side explanatory variables, we can investigate the impact of these factors on housing prices, and examine whether the energy class has some additional independent impact on the transaction price of a dwelling. We also add quarterly time dummies in the model to account for the timevariation in the housing price level, and postal code dummies to account for unobserved timeinvariant neighbourhood attributes that might be correlated with the energy label. We estimate 
similar model for the observed selling time, too, to examine the relationship between energy rating and expected time on market.

As explained in the data section, we use four energy rating groups in the estimations: The above average energy efficiency group $(A B C)$, the average classes ( $D$ and $E$ ), and the low-rated apartments (FG). The aggregation of the highest and lowest energy efficiency groups is preferable as the small number of observations in the $A, B$ and $G$ groups could yield spurious and idiosyncratic coefficient estimates. It is reasonable to consider the $A B C$ class as the highly-rated units for the sake of testing the signalling hypothesis.

Table 3 shows a number of alternative model specifications for the natural log of transaction price. The omitted energy efficiency group in the estimations is $D$. That is, the coefficients on the energy classes show the premium or discount compared with the average efficiency class.

[Table 3 around here]

Specification (1) only includes the energy classifications and no other explanatory variables (except for the time dummies). The point estimates indicate that the average selling price for the high-rated units is $18 \%$ higher and those for the $\mathrm{E}$ and $\mathrm{FG}$ rated units are respectively $8 \%$ and $6 \%$ lower than the mean value of $D$ rated apartments. For the $A B C$ and $E$ classes the price difference also is highly statistically significant. However, the more detailed model specifications show that these observed price differences between the energy rating groups can be explained, to a major extent, by the locational and building characteristics.

The inclusion of the typical variables included in hedonic housing price models to capture the influence of location and physical attributes of an apartment diminishes the absolute values of the coefficient on high-rated units to $3.3 \%$ with a model fit of $86 \%$ (specification 2 ). When controlling more carefully for the locational attributes by adding postal code dummy variables and the neighbourhood characteristics in specification (3), this point estimate further drops to $1.5 \%$, while the model fit substantially increases to $93 \%$. That is, the inclusion of the detailed neighbourhood characteristics that are often absent in related investigations causes a significant decline in the estimated premium for the energy efficient apartments: although the premium remains statistically significant, it is less than half the size shown by specification (2). Moreover, the coefficients on $E$ and FG classes are insignificant in specification (3). Clearly, this points to an omitted variable bias in a model where the road and time distance to the CBD are the only variables reflecting the unit location, and is in line with our third hypothesis. Importantly, the results also give support to our signalling hypothesis, according to which there is a price premium for the high-rated units, whereas 
there is no price discount for the low-rated compared with the average energy performance apartments.

In support of our second hypothesis regarding the independent informational content of the energy ratings, the inclusion of maintenance costs only slightly affects the estimated premium for the $A B C$ class: the point estimate on the $A B C$ group is $1.3 \%$ in model (4). Expectedly, the coefficient decreases as the maintenance costs are controlled for, but this decline is insignificant. Thus, our results provide evidence in support of all our three hypotheses.

We provide further robustness checks in Table A1 in the Appendix in order to investigate whether the finding of a price effect only in the highest energy efficiency class could be due to some form of non-linearity in the hedonic housing valuation that is not accounted for in the models in Table 3 . In specification (1) in Table A1, all the continuous house related characteristics are taken into the main model (Model 4 in Table 3) raised to the third power. The results are largely unchanged, although the point estimate of top rated apartments drops slightly to $1.1 \%$ with a p-value of 0.052 . It should be noted that adding all housing related continuous explanatory variables in non-linear transformations may introduce overspecification into the model which may in turn bias the estimates. Hence, Model 2 in Table A1 presents the regression results for a model in which all insignificant second and third powers are dropped from the specification using backward elimination with a threshold p-value of 0.05 . In this model, the premium on ABC class is practically the same as that reported in Table 3 and the valuation effect remains insignificant for other energy classes. In sum, we conclude that ourresults appear robust to additional non-linearity in the house price valuation identifying equation.

Although this study does not focus on the capitalisation of energy cost savings to housing values per se, a brief quantitative assessment of the obtained coefficients appears in order here. The $0.2 \%$-point difference in the coefficient on ABC class between models (3) and (4) is not likely to provide a clear picture of the capitalisation of energy cost savings into housing value, since the age and condition variables can considerably influence the level of energy costs and may therefore be highly correlated with these costs (that we do not observe separately from the maintenance cost data). In other words, age and condition are likely to include part of the energy cost capitalisation effects in specifications (2) and (3). Therefore, we re-estimate models (3) and (4) without the age and condition variables (Table A2 in the Appendix) and observe that the R-squared remains over $90 \%$ in these specifications. This suggests that the possible omitted variable bias stemming from excluding age and condition is unlikely to be a great concern. The model and coefficients of interests are robust to these changes in specification as the difference in the point estimate of $A B C$ in these models $(0.3 \%$ points) does not notably differ from the baseline models. 
Note also that, given the point estimate of -0.05 (-0.08 in the version excluding age and condition) on maintenance costs and the fact that on average some $30 \%$ of the maintenance costs are related to energy consumption, the results imply that a $50 \%$ drop in energy costs would have a 'pure' price effect (i.e. effect unrelated to the valuation impact of the energy rating) of only $0.8 \%$ (1.2\%). Overall, our analysis does not confirm expected energy cost savings capitalisation but the causal effects warrant more careful investigation in follow-up research.

An inability to detect a sizable capitalisation effect from the current energy cost savings is not necessarily at odds with rational behaviour. The discounted present value of the energy savings is generally only a small proportion of the overall property value. To illustrate this, let us consider the average savings of a typical energy class $C$ unit compared with a $D$ rated apartment. The average annual energy usage is $130 \mathrm{kwh} / \mathrm{m}^{2}$ and $160 \mathrm{kwh} / \mathrm{m}^{2}$ in $\mathrm{C}$ and $\mathrm{D}$, respectively. The average size of an apartment in our sample is $57 \mathrm{~m}^{2}$. Annual savings, with an energy price of $€ 0.068 / \mathrm{kwh}$, is then $€ 116$ per annum (Statistics Finland, 2016). Assuming a real interest rate of $2 \%$ and a risk premium of $3 \%$ (given the uncertainty of the size of savings due to uncertainty in future energy prices and consumption), the present value of energy cost savings over 25 years is about $€ 1700$. Hence the expected average capitalised value of $C$ compared to $D$ would be $€ 1700$ or roughly $1 \%$ of the average price of apartments in our sample. The savings are more substantial at both tails of the energy rating scale. For $A$ and $G$ rated apartments, similar computations yield present values of $€ 4700$ and (minus) $€ 9400$, respectively, but the share of $A$ or $G$ rated apartments in groups $A B C$ and $F G$ is relatively small. Obviously, the present values are greater in absolute value if the real discount rate is smaller than $5 \%$ or if we assume that energy prices grow faster than general price level. For instance, assuming an annual real energy price growth rate of $1 \%$, the present values would be $€ 5200$ for $A$, $€ 1900$ for $D$, and (minus) $€ 10300$ for $G$. In any case, it should be understood that our estimates of cost capitalisation effects in Tables 3 and A2 are only coarse approximations and that individual cost savings may differ widely depending on the assumptions used in the worked examples above.

An obvious follow-on question is why energy consumption for heating and the savings associated with higher energy efficiency do not appear to be fully capitalised into Helsinki apartment prices which seems to contradict the findings of a number of studies from other markets and countries. An obvious explanation may be that investments in energy efficiency tend to be unviable, particularly in times when energy prices are low as has for example been reported by Copiello and Bonifaci (2015). Another, more local, explanation may be the fact that individual occupants have very little control over their heating expenses in apartment buildings as these have district heating and heating bills are split among residents according to apartment size. Hence, there is little incentive for an individual household to be concerned about energy consumption as any excess 
consumption by a particular household is essentially turned from a private into a social cost. For example, Kyrö et al (2011) as well as Heinonen and Junnila (2014) document how this fixed-ratio splitting mechanism stimulates higher aggregate energy consumption in Finnish and Swedish apartment buildings. It would be interesting to investigate further whether purchasers pay the same attention to heating costs when buying an apartment as they would when buying a detached house or an apartment with separate metering and billing or whether the opposite is the case.

Absent energy savings capitalisation, there are several possible explanations for the observed 'independent' premium for high-rated units. First, eco-consumers typically aim to buy above average rated dwellings, thereby inducing higher demand for those units. Second, a small fraction of households may expect energy prices to grow fast so that the expected energy cost increase (or more precisely the increase in excess of current maintenance costs) capitalises, at least to some extent, to the dwelling price if these households choose to buy $A / B / C$-rated units. Third, a pricing difference also could emerge partially due to smaller risk with respect to future obsolescence in the higher-rated units as these units are more likely to comply with future regulatory requirements (Falkenbach et al., 2010). For example, it seems likely that future regulations will become even more stringent, following the European Commission's Energy Performance of Buildings Directive 2010/31 (EPBD) which contains the concept of Nearly-Zero Energy Buildings (NZEB). Kurnitski et al (2015) present scenarios of cost-optimal and nearly-zero energy calculations for residential buildings. As all new buildings are required to meet the NZEB standard by 2020 according to the EPBD, this may disproportionately accelerate the obsolescence of the non-energy-efficient part housing stock.

A potential complication in virtually all hedonic house price models estimated in the literature is that there can be omitted variables which could bias the point estimates and standard errors to some extent. The fit of our more detailed models is approximately $93 \%$, which indicates that no important drivers have been omitted from our specification. Moreover, in addition to the typical explanatory variables included in the previous studies the models include a number of locational characteristics that control for neighbourhood effects that would otherwise remain unobserved - another factor increasing the reliability of our results. Finally, the building and zoning regulation in Finland are very stringent compared to most other countries. This also suggests that the possible unobserved variation in house price drivers is likely to be relatively small.

\section{Liquidity model}

The direction of the impact of energy efficiency ratings on liquidity and time and market is not straightforward from a theoretical perspective. On the one hand, there may be a larger number of potential buyers for an otherwise similar dwelling that is high energy-rated: Our signalling 
hypothesis and the results reported above suggest that there is a set of market participants that aim to buy only high-rated units and are willing to pay a premium for those apartments. Thus, the liquidity of the high-rated units could be better. On the other hand, many owners of high-efficiency units that are about to sell the dwelling - being themselves environmentally aware and oriented may expect to get notable price premiums for their apartments. As most market actors do not pay attention to the energy ratings based on the comments of housing market professionals and on our price estimations, it may take a long time for the seller to match with an equally aware buyer, and the seller may eventually need to substantially drop the required green premium. These potential effects can offset each other, of course. Therefore, the possible liquidity effect is essentially an empirical question.

Table 4 only reports our best model for liquidity, because the key result does not vary across model specifications. The dependent variable is the natural log of the time on market, and the set of explanatory variables contains all the variables included in the most detailed price equation (specification (4) in Table 3). In addition, we add as an explanatory variable the residual series from price equation (4), as the deviation of the selling price of a dwelling compared with its hedonic price can notably affect the selling time based on the search theoretic models of the housing markets (e.g. Krainer, 2001; Novy-Marx, 2009).

\section{[Table 4 around here]}

The estimation results do not provide evidence of a liquidity effect of energy ratings. While the point estimates show a slightly shorter time on market for the high-rated units and a somewhat longer selling time for the E-rated apartments compared with the average energy class $D$, the coefficients are statistically insignificant. Interestingly, higher maintenance costs make an apartment somewhat harder to sell. Similar to the price model, the inclusion of maintenance costs has only a marginal influence on the parameter estimates in the time on market model. In contrast with the price models, the liquidity model explains only some $13 \%$ of the variation in the dependent variable. This implies that a major share of the variation in time on market cannot be explained, at least by the typical explanatory variables, but a bulk of the variation seems to be random across sold units rather than related to the main characteristics of the location or physical structure.

\section{Conclusions}

This study investigates whether energy efficiency ratings, which are mandatory in various forms throughout the European Union, are able to create additional incentives to invest in energy efficient housing. Using a sample of several thousand apartment transactions in the Helsinki market in Finland, we test if higher ratings were significantly associated with higher prices and shorter selling 
times during 2009-2012, controlling for a large number of other property and neighbourhood characteristics.

We find a statistically significant price premium for the high-rated (ABC) apartments even when controlling for the maintenance costs that incorporate the housing company level energy usage. While there is a clear price premium for the most energy efficient class of buildings, the market does not seem to differentiate between low- and medium-rated units. This may arise in a situation where the majority of households do not pay attention to or may not even be aware of the energy ratings whereas environmentally aware households may pay attention to the energy ratings and subsequently target properties with good or excellent ratings. In this situation, segmented demand will arise and price premia will only become observable for the top tier of energy ratings and no differentiation within the mainstream market. We call this the 'green signalling effect' in the housing market that is induced by a niche of consumers aiming to signal their green values, analogous to corporate social responsibility motives observed in the commercial real estate market (Gliedt and Hoicka, 2015). However, the energy ratings do not appear to have a notable influence on the expected time on market when the other relevant variables are controlled for.

The empirical analysis provides some practical implications. The results suggest that the energy ratings have independent valuation effects that can provide incentives to buy and construct energy efficient housing. That is, our results imply that the energy ratings do matter, at least in the upper end of the distribution, even though we find that introducing additional control variables that were not used in most previous studies lead to a smaller green price premium. This could be an important message given that adoption rates of energy performance certificates seem to have been low and declining over time at least in some countries within the European Union (Brounen and Kok, 2011).

More broadly, these empirical results provide important pricing information to real estate developers and investors. For the construction sector, a price premium for higher than average energy efficiency units could potentially provide a signal that is transmitted from the investment market to the space market, subsequently causing incentives for construction companies to construct green apartments and thereby leading to an increase in the supply of green buildings and less energy consumption. However, these price effects, based on our estimations, are not sufficient incentives for building highly energy efficient housing in the area. Thus, the policy recommendation - in order to increase energy efficient new construction - is to either tighten mandatory requirements or to contribute to an increase in the price premium for energy efficient housing. The latter could be achieved by improving the public awareness of energy costs and energy ratings (i.e. by improving economic literacy with respect to housing costs and valuation, and by strengthening the households' green values) or by increasing the expected economic benefits of 
energy efficiency (through taxation or subsidies, for instance). One possible tax policy would be to impose a higher property tax rate on the less energy efficient buildings.

The findings of this paper are not necessarily generalisable to other markets located in different climate conditions. On the one hand, one might expect that higher energy efficiency will generally have a greater premium in the countries where the average energy efficiency standard of housing is notably lower and thereby the difference in the energy efficiency between the average building and the high-rated apartments is much greater - after all, Finland is a market that arguably maintains some of the highest building and energy efficiency standards in the world due to its harsh winters. A gradual tightening of minimum requirements for energy efficiency over the next few years would not necessarily take away the financial incentives to build (or refurbish) above average energy efficient units in countries with much less energy-efficient building stock. On the other hand, energy efficiency may be particularly relevant in a cold climate due to potentially large heating cost differences arising from the quality of insulation. In addition, as our analysis is based on an actual consumption-based rating system, the empirical findings are not necessarily generalisable to countries with appraisal-based or mixed rating regimes.

Follow-up research may explore these issues in greater depth. A particularly attractive opportunity for further analysis arises from the fact that the energy efficiency rating system was switched from a consumption-based system as reflected in this study to one that estimates the hypothetical energy requirements based on the intrinsic energy efficiency quality of a dwelling's components. This would allow to discern different valuation effects of these two fundamentally different efficiency rating philosophies in future research.

\section{Acknowledgments}

We are grateful to two anynomous referees for their valuable comments. Comments from Viggo Mortensen and Maarit Haataja from the Finnish Ministry of the Environmenta and the participants of the ENHR workshop in Aberystwyth helped to improve this paper. The financial support of the RICS Research Trust, the Turku School of Economics Support Foundation, the Academy of Finland, Marjatta and Eino Kolli Foundation, the KIINKO Foundation, and the Cambridge University Land Society (CULS) is gratefully acknowledged.

\section{References}

Aktacir, M.A., Büyükalaca, O., Yılmaz T. (2010) A case study for influence of building thermal insulation on cooling load and air-conditioning system in the hot and humid regions. Applied Energy, 87, 599-607. 
Arumägi, E., Kalamees, T. (2014) Analysis of energy economic renovation for historic wooden apartment buildings in cold climates. Applied Energy, 115, 540-548.

Balaras, C., Droutsa, K., Dascalaki, E., Kontoyiannidis, S. (2005) Heating energy consumption and resulting environmental impact of European apartment buildings. Energy and Buildings,37:429-42.

Banfi, S., Farsi, M., Filippini, M., Jakob, M. (2005) Willingness to pay for energy-saving measures in residential buildings, CEPE Working Paper, No. 41.

Bartik, T.J. (1987) The estimation of demand parameters in hedonic price models. The Journal of Political Economy, 95, 81-88.

Brounen, D., Kok N. (2011) On the economics of energy labels in the housing market. Journal of Environmental Economics and Management, 62, 166-179.

Brounen, D., Kok, N., Quigley, J. M. (2013) Energy literacy, awareness, and conservation behavior of residential households. Energy Economics, 38, 42-50.

Burfurd, I., Gangadharan, L., Nemes, V. (2012) Stars and standards: Energy efficiency in rental markets. Journal of Environmental Economics and Managements, 64, 153-168.

Considine, $T$ (2000) The impacts of weather variations on energy demand and carbon emissions. Resource and Energy Economics, 22, 295-314.

Cooremans, C. (2011) Make it strategic! Financial investment logic is not enough. Energy Efficiency, 4, 473492.

Sergio Copiello, Pietro Bonifaci (2015) Green housing: Toward a new energy efficiency paradox? Cities, 49/15, 76-87.

Deng, Y., Li, Z., Quigley, J.M. (2012) Economic returns to energy-efficient investments in the housing market: evidence from Singapore. Regional Science and Urban Economics, 42, 506-515.

Dian, T.M., Miranowski, J. (1989) Estimating the implicit price of energy efficiency improvements in the residential housing market- a hedonic approach, Journal of Urban Economics, 25, 52-67.

Falkenbach, H., Lindholm, A., Schleich, H. (2010) Environmental sustainability: drivers for the real estate investor. Journal of Real Estate Literature, 18, 201-223.

Friedman, M. (1953) Choice, chance, and the personal distribution of income. Journal of Political Economy, 61, 277-290.

Fuerst, F., McAllister, P., Nanda, A., Wyatt, P. (2015) Does energy efficiency matter to home-buyers? An investigation of EPC ratings and transaction prices in England. Energy Economics, 48, 145-156.

Giles, D. (2011) Interpreting dummy variables in semi-logarithmic regression models: Exact distributional results. Working Paper University of Victoria, Department of Economics.

Gillingham, K., Newell, R., Palmer, K. (2006) Energy efficiency policies: a retrospective examination. Annual Review of Environment and Resources, 31, 161-192.

Gliedt, T., Hoicka, C.E. (2015) Energy upgrades as financial or strategic investment? Energy star property owners and managers improving building energy performance. Applied Energy, 147, 430-443.

Harjunen, O., Liski, M. (2014) Not so myopic consumers - evidence of capitalisation of energy technologies in a housing market. CESifo Working Paper Series, No. 4989.

Heinonen, J., Junnila, S. (2014) Residential energy consumption patterns and the overall housing energy requirements of urban and rural households in Finland. Energy and Buildings, 76, 295-303.

Jackson, J. (2010) Promoting energy efficiency investment with risk management decision tools. Energy Policy, 38, 3865-3873.

Joelsson A, Gustavsson L. (2009) District heating and energy efficiency in detached houses of differing size and construction. Applied Energy, 86,126-34.

Kahn, M.E., Kok, N. (2014) The capitalisation of green labels in the California housing market. Regional Science and Urban Economics, 47, 25-34. 
Kauffman, D., Garafola, N. (2016). Quantifying the value of home energy improvements. In B. G. Southwell, E. M. B. Doran, L. S. Richman (Eds.), Innovations in home energy use: a sourcebook for behavior change (pp. 31-59). Research Triangle Park, NC: RTI Press.

Kholodilin, K.A., Michelsen, C. (2014) The market value of energy efficiency in buildings and the mode of tenure. SSRN Working Paper.

Krainer, J. (2001) A theory of liquidity in residential real estate markets. Journal of Urban Economics, 49, 3253.

Kurnitski, J., Saari, A., Kalamees, T., Vuolle, M., Niemelä, J., \& Tark, T. (2011). Cost optimal and nearly zero (nZEB) energy performance calculations for residential buildings with REHVA definition for nZEB national implementation. Energy and Buildings, 43(11), 3279-3288.

Kyrö, R., Heinonen, J., Säynäjoki, A., Junnila, S. (2011) Occupants have little influence on the overall energy consumption in district heated apartment buildings. Energy and Buildings, 43, 3484-3490.

Lechtenböhmer S, Schüring A. (2010) The potential for large-scale savings from insulating residential buildings in the EU. Energy Efficiency 4, 257-70.

Lommerud, K.E. (1989) Educational subsidies when relative income matters. Oxford Economic Papers, 41, 640-652.

Malpezzi, S. (2003) Hedonic pricing models: a selective and applied review. Section in Housing Economics and Public Policy: Essays in Honor of Duncan Maclennan.

Mandell, S. Wilhelmsson, M. (2011) Willingness to pay for sustainable housing. Journal of Housing Research, 20, 35-51.

Matisoff, D.C., Noonan, D.S., Mazzolini, A.M. (2014) Performance or marketing benefits? The case of LEED certification. Environmental science \& technology, 48, 2001-2007.

MetropAccess (2014). Multimodal accessibility measures in the Helsinki metropolitan region: MetropAccessTravel Time Matrix. University of Helsinki, The Department of Geosciences and Geography. http://blogs.helsinki.fi/accessibility/data/

Moustris, K.P., Nastos, P.T., Bartzokas, A., Larissi, I.K., Zacharia, P.T., Paliatsos, A.G. (2014) Energy consumption based on heating/cooling degree days within the urban environment of Athens, Greece. Theoretical and Applied Climatology, 122, 1-13.

Novy-Marx, R. (2009) Hot and cold markets. Real Estate Economics, 37, 1-22.

Ottelin, J., Heinonen, J., Junnila, S. (2015) New energy efficient housing has reduced carbon footprints in outer but not in inner urban areas. Environmental Science and Technology, 49, 9574-9583.

Popescu, D., Bienert, S., Schützenhofer, C., Boazu, R. (2012) Impact of energy efficiency measures on the economic value of buildings. Applied Energy, 89, 454-463.

Rahman, M.M., Rasul, M.G, Khan, M.M.K. (2010) Energy conservation measures in an institutional building in sub-tropical climate in Australia. Applied Energy , 87, 2994-3004.

Ray, D., Robson, A. (2012) Status, intertemporal choice, and Rrsk-taking. Econometrica, 80, 1505-1531.

Rogers, W.H. (1993) Regression standard errors in clustered samples. Stata Technical Bulletin 13, 19-23.

Rosen, S. (1974) Hedonic prices and implicit markets, product differentiation in pure competition. Journal of Political Economy, 82, 34-55.

Statistics Finland (2016): Energy prices. Data.

Szumilo, N., Fuerst, F. (2014). The operating expense puzzle of US green office buildings. Journal of Sustainable Real Estate, 5, 86-110.

Thorsnes, P., Bishop, T. (2013) The value of basic building code insulation. Energy Economics, 37, 68-81.

Wameling, T. (2010) Immobilienwert und Energiebedarf. Einfluss energetischer Beschaffenheiten auf Verkehrswerte von Immobilien, Fraunhofer IRB Verlag, Stuttgart. 
Warner, J. T., Pleeter, S. (2001) The personal discount rate: Evidence from military downsizing programs. American Economic Review, 91, 33-53.

Wong-Parodi, G., Kirby, J., Miller, R. Girard, M. (2016). Considering the effect of incorporating home energy performance ratings into real estate listings. In B. G. Southwell, E. M. B. Doran, L. S. Richman (Eds.), Innovations in home energy use: a sourcebook for behavior change (pp. 61-85). Research Triangle Park, NC: RTI Press.

Zheng, S., Kahn, M.E. (2008) Land and residential property markets in a booming economy: New evidence from Beijing. Journal of Urban Economics, 63, 743-757.

Zheng, S., Wu, J., Kahn, M.E., Deng, Y. (2012) The nascent market for "green" real estate in Beijing. European Economic Review, 56, 974-984. 


\begin{tabular}{|c|c|c|c|c|c|c|c|c|}
\hline & \multicolumn{2}{|c|}{ Energy ABC } & \multicolumn{2}{|c|}{ Energy D } & \multicolumn{2}{|c|}{ Energy E } & \multicolumn{2}{|c|}{ Energy FG } \\
\hline & \multicolumn{2}{|c|}{$\mathrm{N}=631$} & \multicolumn{2}{|c|}{$\mathrm{N}=2731$} & \multicolumn{2}{|c|}{$\mathrm{N}=2379$} & \multicolumn{2}{|c|}{$\mathrm{N}=453$} \\
\hline & mean & std.dev & mean & std.dev & mean & std.dev & mean & std.dev \\
\hline \multicolumn{9}{|c|}{ Apartment and building charateristics } \\
\hline Price $\left(€ / \mathrm{m}^{2}\right)^{\mathbf{A}}$ & 3656 & 1181 & 3343 & 1211 & 3414 & 1208 & 3694 & 1139 \\
\hline Maintenance costs $\left(€ / \mathrm{m}^{2}\right)$ & 3.08 & 0.75 & 3.33 & 0.76 & 3.64 & 0.78 & 3.74 & 0.91 \\
\hline Size $\left(\mathrm{m}^{2}\right)$ & 63.9 & 24.1 & 59.1 & 21.6 & 53.7 & 20.7 & 50.8 & 21.1 \\
\hline Age & 30.1 & 29.0 & 42.0 & 24.6 & 50.2 & 19.8 & 54.2 & 17.8 \\
\hline \multicolumn{9}{|l|}{ Condition } \\
\hline -very good & 0.20 & 0.40 & 0.09 & 0.29 & 0.06 & 0.23 & 0.05 & 0.21 \\
\hline$-\operatorname{good}$ & 0.58 & 0.49 & 0.54 & 0.50 & 0.50 & 0.50 & 0.48 & 0.50 \\
\hline -satisfactory & 0.20 & 0.40 & 0.35 & 0.48 & 0.41 & 0.49 & 0.44 & 0.50 \\
\hline -bad & 0.02 & 0.14 & 0.03 & 0.16 & 0.03 & 0.17 & 0.03 & 0.18 \\
\hline Sauna (dummy) & 0.52 & 0.50 & 0.25 & 0.43 & 0.12 & 0.32 & 0.09 & 0.29 \\
\hline Floor & 3.31 & 2.03 & 3.09 & 1.78 & 2.96 & 1.76 & 3.08 & 2.01 \\
\hline Maximum floor & 5.67 & 2.39 & 5.24 & 2.12 & 4.90 & 2.01 & 4.94 & 2.41 \\
\hline Penthouse (dummy) & 0.18 & 0.38 & 0.21 & 0.41 & 0.23 & 0.42 & 0.25 & 0.44 \\
\hline Road distance to CBD (km) & 12.3 & 6.30 & 11.6 & 6.46 & 10.0 & 5.93 & 8.56 & 5.36 \\
\hline Travel time to CBD (minutes) ${ }^{\mathbf{B}}$ & 28.4 & 10.1 & 27.1 & 10.6 & 25.3 & 10.0 & 23.3 & 9.66 \\
\hline \multicolumn{9}{|l|}{ Neighborhood characteristics } \\
\hline Homeownership rate & 0.53 & 0.19 & 0.52 & 0.18 & 0.52 & 0.16 & 0.52 & 0.15 \\
\hline Mean income per capita ( $€ /$ year) & 27896 & 5637 & 25968 & 4632 & 24928 & 3942 & 25046 & 3822 \\
\hline College degree & 0.31 & 0.12 & 0.28 & 0.12 & 0.27 & 0.11 & 0.29 & 0.10 \\
\hline Unemployment rate & 0.05 & 0.03 & 0.06 & 0.04 & 0.07 & 0.04 & 0.06 & 0.03 \\
\hline Pensioner share & 0.18 & 0.08 & 0.21 & 0.09 & 0.23 & 0.09 & 0.23 & 0.11 \\
\hline Share of families with children & 0.18 & 0.09 & 0.16 & 0.08 & 0.14 & 0.08 & 0.12 & 0.07 \\
\hline Service jobs/capita & 0.19 & 0.38 & 0.30 & 0.81 & 0.32 & 0.93 & 0.38 & 0.95 \\
\hline Number of buildings & 19.1 & 10.4 & 18.1 & 10.1 & 18.5 & 11.0 & 19.2 & 11.4 \\
\hline Mean dwelling size $\left(\mathrm{m}^{2}\right)$ & 63.7 & 11.2 & 59.5 & 10.9 & 56.2 & 11.3 & 54.2 & 11.8 \\
\hline Population & 687 & 421 & 735 & 510 & 735 & 530 & 721 & 521 \\
\hline
\end{tabular}

Notes: ${ }^{A}$ Prices are deflated to year 2013 using consumer price index. ${ }^{B}$ Travel time using public transportation. 
Table 2: Regression estimates for maintenance costs

Dependent variable: log of maintenance costs per sqm

Energy class ABC

$-0.029 * *$

[0.014]

Energy class E

$0.048 * * *$

[0.012]

Energy class FG

R-squared

$\mathbf{N}$

6194

Year quarter fixed effects

Postal code fixed effects

yes

House characteristics ${ }^{\mathrm{A}}$

yes

CBD distance ${ }^{B}$

yes

Neigh. Characteristics ${ }^{\mathrm{C}}$

yes

\begin{abstract}
Notes: The omitted energy class is D. Estimated coefficient is statistically significant at $* * * 1 \%$ level, ** 5\% level, * 10\% level. Standard errors are clustered within postal code area, number of clusters is 118 . ${ }^{\mathrm{A}}$ House characteristics include: age raised to the second power, dummies for condition (bad, satisfactory, good, very good), dummy for sauna, dummies for floor (less than 4, 4 to 6, 7 to 9, more than 9) dummies for maximum floor (less than 4, 4 to 6, 7 to 9, more than 9) and dummy for penthouse. ${ }^{\mathrm{B}}$ CBD distance is measured in road distance and in travel time using public transportation. ${ }^{\mathrm{C}}$ Neighborhood controls include: share of homeowners, log of mean income, share with college education, share of unemployed, share of pensioners, share of families with children, number of buildings, log of mean house area, and population.
\end{abstract}


Table 3: Regression estimates for transaction prices

(1)

(2)

(3)

(4)

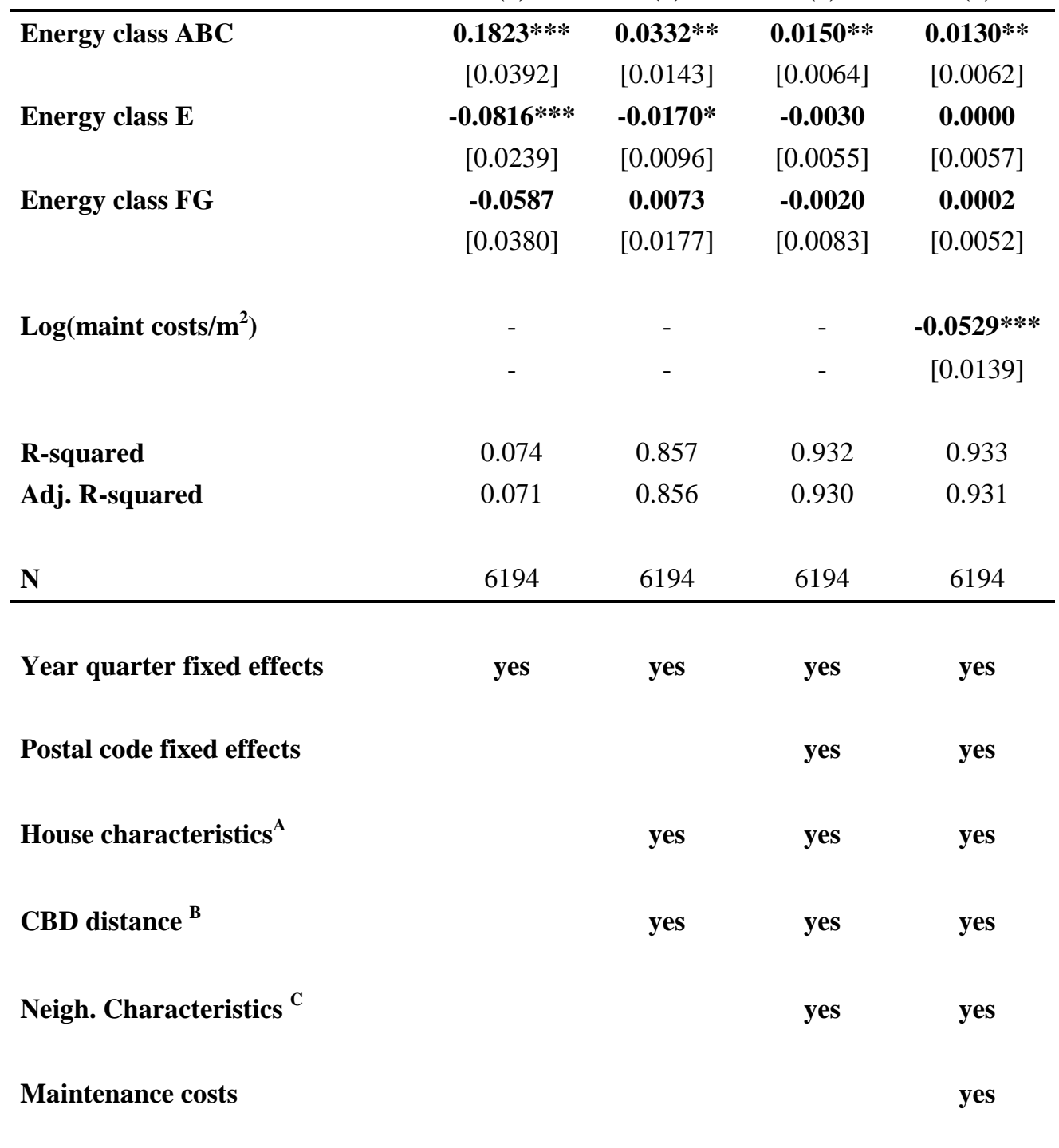

Notes: The omitted energy class is D. Estimated coefficient is statistically significant at $* * *$ $1 \%$ level, ** 5\% level, * 10\% level. Standard errors are clustered within postal code area, number of clusters is $118 .{ }^{\mathrm{A}}$ House characteristics include: area raised to the third power, age raised to the second power, dummies for condition (bad, satisfactory, good, very good), dummy for sauna, dummies for floor (less than 4,4 to 6,7 to 9 , more than 9), dummies for maximum floor (less than 4, 4 to 6,7 to 9 , more than 9), and dummy for penthouse. ${ }^{\mathrm{B}} \mathrm{CBD}$ distance is measured in road distance and in travel time using public transportation. ${ }^{\mathrm{C}}$ Neighborhood controls include: share of homeowners, log of mean income, share with college education, share of unemployed, share of pensioners, share of families with children, number of buildings, log of mean house area, and population. 
Table 4: Regression estimates for time on market

\section{Dependent variable: log of time on market}

Energy class ABC

Energy class E

\footnotetext{
Notes: The omitted energy class is D. Dependent variable: log of saletime in days+1 (some observation that were sold the first day they were on the market). Estimated coefficient is statistically significant at *** 1\% level, ** 5\% level, * 10\% level. Standard errors are clustered within postal code area, number of clusters is $118 .{ }^{\mathrm{A}}$ House characteristics include: residual of the most extensive price estimation, log of maintenance costs, area raised to the third power, age raised to the third power, condition, dummy for sauna, dummies for floor (less than 4, 4 to 6,7 to 9 , more than 9) dummies for maximum floor (less than 4, 4 to 6, 7 to 9, more than 9), and dummy for penthouse. ${ }^{\mathrm{B}}$ CBD distance is measured in road distance and in travel time using public transportation. ${ }^{\mathrm{C}}$ Neighborhood controls include: share of homeowners, log of mean income, share with college education, share of unemployed, share of pensioners, share of families with children, number of buildings, log of mean house area, and population.
} 
Figure 1: Geographic distribution of the observed transactions

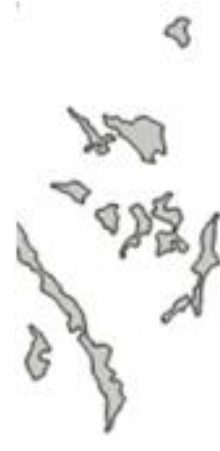

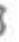

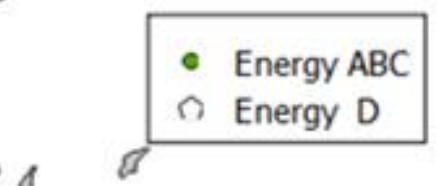

3 \%

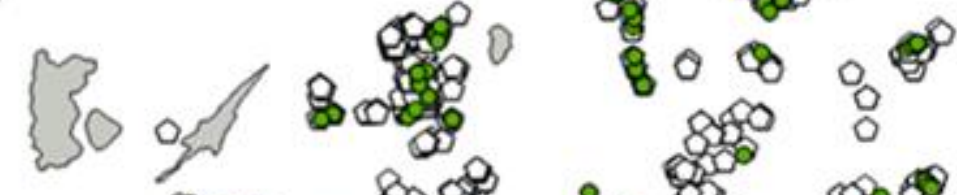

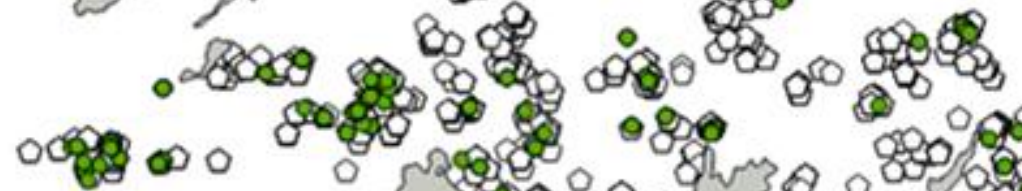
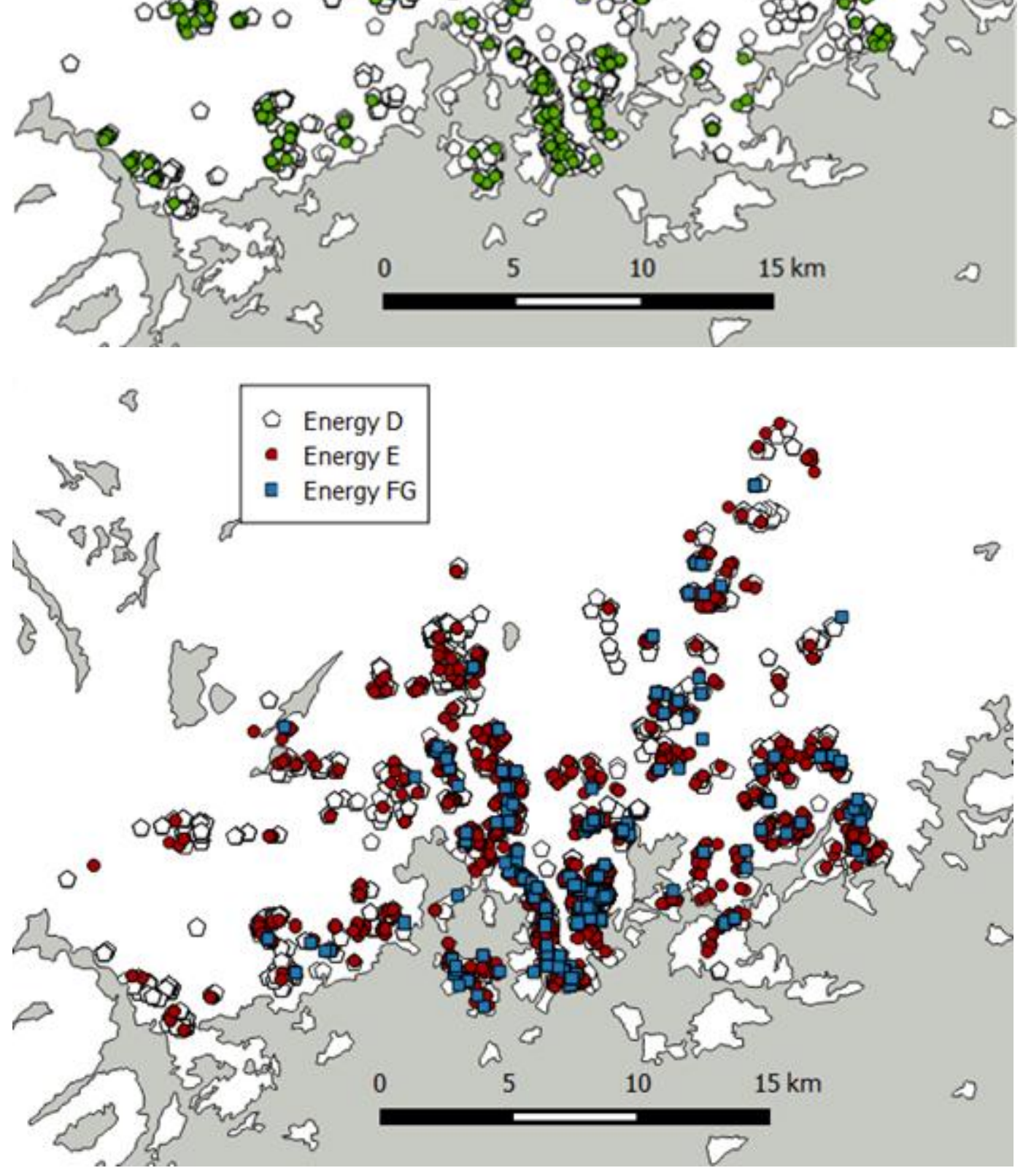
Table A1: Robustness check form of the hedonic model

Dependent variable: log of sales price

(1)

Energy class ABC

Energy class E

Energy class FG
0.0110*

[0.0056]

0.0005

[0.0056]

0.0081

[0.0084]

0.935

0.933

6194

yes

Year quarter fixed effects

Postal code fixed effects

House characteristics

CBD distance

Neigh. Characteristics

Maintenance costs yes

yes

yes

yes

yes yes

(2)

$0.0134 * *$

[0.0058]

0.0008

[0.0057]

0.0093

[0.0081]

0.934

0.933

6194

yes

yes

(area raised to the third power, age raised to the third power)

yes

(road distance raised to the second power)

yes

yes

(only the third power)

Notes: (1) Results of a regression where all continuous house related controls are taken into the main model raised to the third power (road distance to CBD, travel time to CBD, area, age, and maintenance costs). (2) Results of a regression where backward elimination (with a threshold p-value of 0.05) is performed for continuous house and neighborhood characteristics used in column (1). The omitted energy class is D. Estimated coefficient is statistically significant at $* * * 1 \%$ level, ** 5\% level, * $10 \%$ level. Standard errors are clustered within postal code area, number of clusters is 118 . 
Dependent variable: log of sales price

\begin{tabular}{|c|c|c|}
\hline & (1) & (2) \\
\hline \multirow[t]{2}{*}{ Energy class ABC } & $0.0374 * * *$ & $0.0345 * * *$ \\
\hline & {$[0.0010]$} & [0.0096] \\
\hline \multirow[t]{2}{*}{ Energy class $\mathbf{E}$} & -0.0119 & -0.0081 \\
\hline & {$[0.0055]$} & {$[0.0058]$} \\
\hline \multirow[t]{2}{*}{ Energy class FG } & -0.0143 & -0.0098 \\
\hline & {$[0.0102]$} & [0.0099] \\
\hline \multirow[t]{2}{*}{$\log \left(\right.$ maint $\left.\operatorname{costs} / \mathbf{m}^{2}\right)$} & - & $-0.0794 * * *$ \\
\hline & - & [0.0177] \\
\hline R-squared & 0.907 & 0.909 \\
\hline Adj. R-squared & 0.905 & 0.906 \\
\hline $\mathbf{N}$ & 6194 & 6194 \\
\hline
\end{tabular}

Year quarter fixed effects

yes

yes

Postal code fixed effects

yes

yes

House characteristics ${ }^{\mathrm{A}}$

yes

yes

CBD distance ${ }^{B}$

yes

yes

Neigh. Characteristics ${ }^{\mathrm{C}}$

yes

yes

Maintenance costs

yes

yes

Notes: The omitted energy class is D. Estimated coefficient is statistically significant at $* * * 1 \%$ level, ** 5\% level, * 10\% level. Standard errors are clustered within postal code area, number of clusters is 118. ${ }^{\text {A }}$ House characteristics include: area raised to the third power, dummy for sauna, dummies for floor (less than 4, 4 to 6, 7 to 9, more than 9), dummies for maximum floor (less than 4, 4 to 6, 7 to 9, more than 9), and dummy for penthouse. ${ }^{B}$ CBD distance is measured in road distance and in travel time using public transportation. ${ }^{\mathrm{C}}$ Neighborhood controls include: share of homeowners, log of mean income, share with college education, share of unemployed, share of pensioners, share of families with children, number of buildings, log of mean house area, and population. 